\title{
Temporal parameters in the acquisition of a free-operant avoidance response in human subjects
}

\author{
Robert Ader and Joseph Seibettal \\ UNIVERSITY OF ROCHESTER SCHOOL OF MEDICINE AND DENTISTRY
}

\begin{abstract}
Male, medical and graduate students were subjected to a nondiscriminated avoidance regimen under different combinations of SS and RS intervals. Acquisition of the avoidance response was found to be a function of the $\mathrm{RS} / \mathrm{SS}$ ratio; the most rapid acquisition occurring at ratios of $2: 1$ or greater.

\section{Problem}

The experimental analysis of operant behavior has been devoted, primarily, to the study of the maintenance of such behavior and the changes effected by the introduction of various experimental manipulations. Little attention has been directed to the functional relations between those parameters of the conditioning situation responsible for acquisition of the response. With respect to free-operant, or nondiscriminated, avoidance conditioning (Sidman, 1953a), in particular, few studies have been concerned with acquisition. One exception is the study by Black \& Morse (1961) who found that, using a constant RS interval of $30 \mathrm{sec}$, acquisition of a barrier-jumping response in dogs could be achieved with an SS interval of 4 sec., but could not be accomplished with an SS interval of $15 \mathrm{sec}$.

Previous research (Ader \& Tatum, 1961, 1963; Stone, 1961) has demonstrated the feasibility of applying the free-operant avoidance technique to human subjects, but provided no data on the conditions which determine if and when an individual will acquire the avoidance response. The present experiment was specifically directed to acquisition of nondiscriminated avoidance behavior in human subjects under those temporal parameters of the conditioning regimen used by Sidman (1953b) to investigate the maintenance of such behavior in the rat.
\end{abstract}

\section{Method}

The subjects (Ss) were 27 male, medical and graduate students between 22 and $30 \mathrm{yr}$. of age. These were volunteers who were told only that they would be paid $\$ 7.50$ for an experiment that would be conducted in two sessions. During the first session Ss were given a battery of psychological tests. These data are described separately (Weiner \& Ader, 1965). The present report is concerned solely with the acquisition data from the second session during which conditioning occurred.

When Ss arrived for the conditioning session they were seated in a chair in front of a table on which a red button had been fastened, and EKG electrodes were attached to one leg. No instructions were given as to the purpose of the experiment or how $\mathrm{S}$ was supposed to behave. In an (unsuccessful) effort to increase the percentage of Ss that would respond by pressing the available button, our instructions included the statement that, "This is not an endurance task and your performance will not determine the length of the session." In all other respects our instructions and procedure were the same as those detailed earlier (Ader \& Tatum, 1961).

Electric shocks were administered through the EKG electrodes by a Grass (S5) stimulator. The interval between successive shocks, the shock-shock (SS) interval was either 5,10 , or 15 sec., and the interval by which a response delayed subsequent shock, the responseshock (RS) interval, varied from 7.5 to $40 \mathrm{sec}$. Each $\mathrm{S}$ was randomly assigned to one particular combination of $\mathrm{SS}$ and RS intervals as given in Table 1. Acquisition of the avoidance response was defined as the time between performance of the first response and the beginning of the first 5 -min. period during which $\mathrm{S}$ avoided at least $80 \%$ of the scheduled shocks. Conditioning continued for $60 \mathrm{~min}$. following acquisition.

\section{Results}

Of the $27 \mathrm{Ss}$, one was eliminated after reporting that he was familiar with the work of Brady (1958) on the avoidance conditioning of monkeys and its effects on gastric ulceration. Thirteen of the Ss were classified as "learners," 11 Ss (only 2 of which made any responses) were "non-learners," and 2 Ss "walked-out" of the experiment. These figures correspond closely to those obtained in our first population (Ader \& Tatum, 1961). The remaining results describe the behavior of the $13 \mathrm{Ss}$ who acquired the avoidance response.

Table 1 contains performance measures obtained from the conditioning session. As can be seen the time required before Ss made their initial response was unrelated to the SS interval. Also, there was no relationship between the time required to make the first response and the time required to attain the acquisition criterion $(\mathrm{rho}=.25)$.

Time to reach the criterion of acquisition ( $\pm 5 \mathrm{sec}$.) was computed from the point at which $\mathrm{S}$ made his first response. These data indicate that at each SS interval an increase in the $\mathrm{RS}$ interval resulted in an increase in the rate of acquisition. That it is not the RS interval, alone, which accounts for these findings is suggested by the fact that, for those RS intervals at which there were 2 or $3 \mathrm{Ss}$, rate of acquisition shows considerable variability. Much of this variability disappears when the acquisition data are presented as a function of the ratio between the RS and SS intervals (Fig. 1). Here it can be seen that the greater the RS/SS ratio, the 


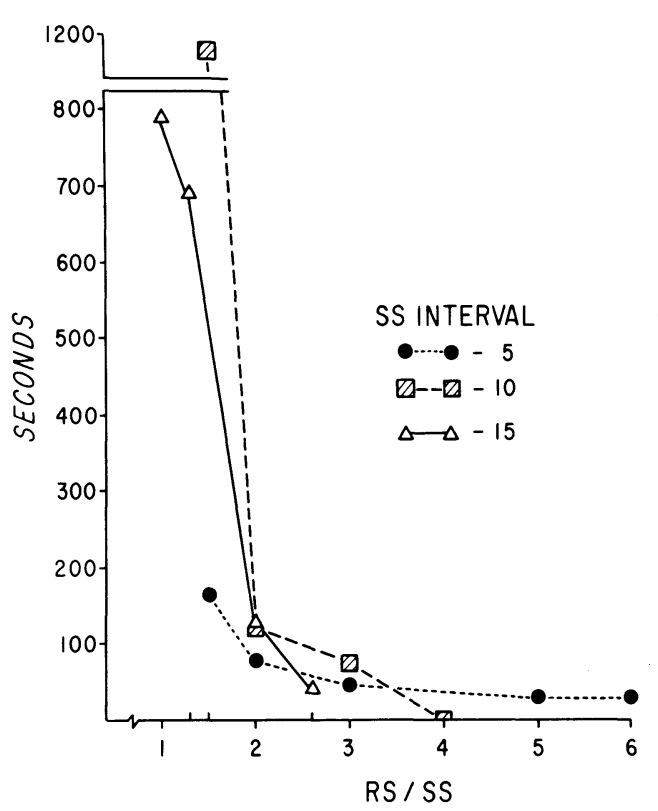

Fig. 1. Time required to attain the criterion of acquisition as a function of the ratio between the RS and SS interval.

faster the acquisition. Ratios equal to or greater than $2: 1$ resulted in rapid acquisition with little variability between $\mathrm{Ss}$, whereas ratios of less than 2:1 effected much slower rates of acquisition and relatively high inter-subject variability.

\section{Discussion}

The best description of the relationship between acquisition of a free-operant avoidance response and the temporal parameters of the conditioning situation appears to be that acquisition is a function of the RS/SS ratio, and the acquisition is facilitated when the ratio is at or beyond $2: 1$. Considering the relatively small number of Ss and the limited number of SS-RS combinations, it might be more conservative, for the present, to simply conclude that acquisition rates are significantly increased with $\mathrm{RS} / \mathrm{SS}$ ratios equal to or greater than $2: 1$ as compared to lesser ratios. As is evident from Fig. 1, there is no overlap in acquisition scores for Ss in these dichotomized groups.

These data obtained from human Ss are quite consistent with the data obtained from dogs (Black \& Morse, 1961). All 7 of the dogs conditioned under SS= 4 and $\mathrm{RS}=30(\mathrm{RS} / \mathrm{SS}=7.5: 1)$ acquired the avoidance response, whereas none of the 3 dogs tested under $\mathrm{SS}=15$ and $\mathrm{RS}=30 \quad(\mathrm{RS} / \mathrm{SS}=2: 1)$ were able to learn. Holding the RS interval constant and varying the SS interval also changes the RS/SS ratio. Therefore, these data may be interpreted to be a function, not of the SS intervals, per se, but of the RS/SS ratio.

Initial responses in the nondiscriminated avoidance situation almost invariably follow immediately upon the receipt of an electric shock. In order for reinforcement to be effective it must first be perceived by the subject, which suggests that one explanation for. the finding of increased rates of acquisition with increased RS/SS ratios (at least for those schedules where RS is greater than SS) would be that the greater the relative difference between the $\mathrm{RS}$ and $\mathrm{SS}$ intervals the more readily the subject is able to perceive the delay in subsequent shocks effected by his responses.

\section{References}

ADER, R., \& TATUM, R. Free-operant avoidance conditioning in human subjects. J. exp. Anal. Beh., 1961, 4, 275-276.

ADER, R., \& TATUM, R. Free-operant avoidance conditioning in individual and paired human subjects. J.exp.Anal.Beh., 1963, 6, 357-359.

BLACK, A. H., \& MORSE, PATRICIA Avoidance learning in dogs without a warning stimulus. J.exp. Anal.Beh., 1961, 4, 17-23. BRADY, J. V. Ulcers in executive monkeys. Scient. Amer., 1958, 199, 95-104.

SIDMAN, M. Avoidance conditioning with brief shock and no exteroceptive warning signal. Science, 1953, 118, 157-158. (a)

SIDMAN, M. Two temporal parameters of the maintenance of avoidance behavior by the white rat. J.comp. physiol. Psychol., 1953, 46, 253-261. (b)

STONE, G. C. Nondiscriminated avoidance behavior in human subjects. Science, 1961, 133, 641-642.

WEINER, I. B., \& ADER, R. Direction of aggression and adaptation to free-operant avoidance conditioning. J. pers. soc. Psychol., 1965, in press.

Note

1. United States Public Health Service Service Summer Medical Student Research Fellow. 